\title{
RANCANGAN SISTEM INFORMASI APLIKASI OLAH DATA PASIEN PADA KLINIK RIFELINA KOTA DEPOK
}

\author{
Ade Yulina ${ }^{1}$,Bondan Dwi Hatmoko ${ }^{2}$,Kevin Septianzah ${ }^{3}$ \\ Program Studi Informatika, Fakultas Teknik dan Ilmu Komputer, Universitas Indraprasta PGRI \\ Jalan Raya Tengah No 80, Kelurahan Gedong, Pasar Rebo, Jakarta Timur \\ adeyulina389@gmail.com¹,royfoi@yahoo.co.id ${ }^{2}$, kevin.septianzah24@gmail.com³
}

\begin{abstract}
Abstrak
Tujuan dari penelitian adalah untuk menggantikan rancangan sistem manual olah data pasien di Klinik Rifelina menjadi rancangan sistem komputerisasi. Metode penelitian yang digunakan untuk merancang sistem informasi pengolahan data pasien ini adalah dengan menggunakan metode analisis data, observasi lapangan dan menggunakan metode kuantitatif dengan java dan MySQL. Selain itu peneliti juga menggunakan metode wawancara, untuk mendapatkan data lebih lengkap. Setelah peneliti merancang dan menganalisa aplikasi sistem informasi pengolahan data pasien ini, maka peneliti dapat menarik kesimpulan bahwa dibuatnya aplikasi sistem informasi pengolahan data pasien Klinik Rifelina Depok dengan menggunakan java dapat bermanfaat sebagai alat semua kegiatan yang berhubungan dengan pengolahan data pasien agar dapat berjalan dengan baik dan lancar.
\end{abstract}

Kata Kunci: Rancangan Sistem, Sistem Data Pasien, Klinik, Java, MySQL.

\begin{abstract}
The purpose of the research is to replace the design of a manual system of patient data at Rifelina Clinic to draft computerized system. The research method used to design this patient data processing information system is to use data analysis method, field observation and quantitative method using Java and MySQL. In addition researchers also use methods of interviews, to get more complete data. After the researchers designed and analyzed the application of this patient data processing information system, researchers can draw conclusions that the application of information system data processing of patients Rifelina clinic in Depok by using Java can Useful as a tool for all activities related to the processing of patient data to be able to run well and smoothly.
\end{abstract}

Keywords: System Design, Patient Data System, Clinic, Java, MySQL.

\section{PENDAHULUAN}

Kesehatan merupakan suatu hal yang sangat penting bagi manusia untuk kehidupan yang dijalaninya. Bahkan pepatah berkata bahwa sehat itu mahal, sering kita lihat bahwa banyak orang rela mengobarkan uangnya demi menjadi sehat kembali namun kesehatan sering luput dari mata manusia itu sendiri. Mulai dari terlalu sibuk, memakan makanan yang tidak sehat, hingga olahraga kurang teratur-pun dapat menimbulkan penyakit. Salah satu pilihan masyarakat dalam mengobati penyakit yang di deritanya adalah berobat ke klinik kesehatan. Klinik merupakan organisasi atau lembaga bidang kesehatan yang bergerak dalam penyediaan pelayanan kesehatan diagnosa dan pengobatan, biasanya terhadap suatu gangguan kesehatan. Seperti yang kita ketahui bahwa suatu klinik kesehatan memiliki data yang kompleks. Data yang di kelola sebuah klinik pada umumnya berupa data pasien, catatan medis dan data obat. Mengelola data sebuah klinik tentunya merupakan hal yang sangat rumit dan membutuhkan waktu yang cukup banyak, terutama jika di kelola secara manual. Dalam hal pengolahan data sebuah klinik yang belum memakai sistem informasi berbasis komputer, dimana sistem pengolahan datanya sampai saat ini masih manual. Proses pendaftaran masih dilakukan secara sederhana dengan menulis data pasien ke dalam sebuah kartu dan buku. Sehingga perlu ruang penyimpanan data pasien, perhitungan pembayaran dapat menimbulkan terjadinya kesalahan perhitungan maupun kesalahan penulisan data sehingga keamanan data yang kurang terjamin merupakan permasalahan yang harus diperhatikan. Proses ini dirasakan kurang efektif, dikarenakan petugas seringkali mendapatkan hambatan pada saat pencarian data pasien 
ketika dibutuhkan apabila data pasien yang ada cukup banyak. Menurut Jogiyanto (2010), Perancangan adalah desain yang menentukan bagaimana suatu sistem akan menyelesaikan apa yang harus di selesaikan". Informasi adalah data yang telah diklasifikasikan atau diolah dan diinterpresentasikan untuk digunakan dalam proses pengambilan keputusan (Sutabri, 2012). Menurut Sukamto et al.(2013), Kamus data adalah kumpulan daftar elemen data yang mengalir pada sistem perangkat lunak sehingga masukan (input) dan keluaran (output) dapat dipahami secara umum".

\section{PENELITIAN RELEVAN}

Hasil penelitian terdahulu dapat dipakai sebagai acuan untuk melakukan penelitian selanjutnya. Meskipun ada perbedaan pada objek atau variabel yang di teliti. Penelitian tersebut dapat dijadikan sebagai gambaran bagi peneliti berikutnya untuk melakukan penelitian. Peneliti mendapatkan beberapa penelitian yang berkaitan dengan aplikasi olah data pada klinik. Pada penelitian pertama membuat aplikasi olah data pasien menggunakan $Q R$ code (Irawan, 2017) dan penelitian kedua membuat aplikasi olah data pembayaran pada klinik (Oktavia, 2017). Dari kedua peneliti tersebut , maka peneliti memutuskan untuk meninjau lebih lanjut kedua penelitian dari kedua peneliti tersebut yang dianggap relevan dengan penelitian yang bersangkutan. Kedua penelitian tersebut, yaitu Rancangan Sistem Layanan Informasi Pasien Quick Response Code Menggunakan Java Netbeans Pada Klinik dr. Hasto Medika dan Perancangan Sistem Informasi Pengolahan Data Pasien Klinik dr. Delly di Kabupaten Bogor Berbasis Java. Dari judul penelitian tersebut terdapat perbedaan metodologi penelitian yang akan dilaksanakan serta terdapat perbedaan objek penelitian. Oleh karena itu, peneliti akan meninjau lebih lanjut penelitian yang membahas mengenai olah data menggunakan metodologi yang berbeda dan dapat mengembangkan aplikasi olah data.

\section{METODE PENELITIAN}

Analisis Deskriptif merupakan alat yang dapat digunakan untuk melakukan dan mencapai suatu penelitian yang disusun secara teratur dan logis yang dituangkan dalam suatu rencana dalam pengumpulan data dan analisis data adalah metode analisis kualitatif dengan pendekatan penelitian analisis deskriptif. Penelitian ini mempelajari masalah-masalah dalam masyarakat, termasuk tentang hubungan, kegiatan, sikap, pandangan serta proses yang sedang berlangsung (Nugroho, 2013). Model Waterfall merupakan salah satu model pengembangan perangkat lunak yang ada di dalam model SDLC (Sequencial Development Life Cycle) (Rizky, 2011).

Untuk teknik pengumpulan data diantaranya interview dan observation. Interview (wawancara) diadakan tanya jawab kepada bagian Sistem Informasi Administrasi Pelayanan Kesehatan. Lalu dilakukan wawancara langsung dengan beberapa pegawai mengenai kondisi sistem pengolahan data pasien Klinik Rifelina yang berjalan dan Observation (pengamatan) teknik pengumpulan data dengan diberikan beberapa dokumen mengenai sistem pengolahan data pasien Klinik Rifelina di Kota Depok oleh bagian Administrasi.

\section{HASIL DAN PEMBAHASAN \\ Analisis Kebutuhan}

Analisa kebutuhan berguna untuk mendapatkan data-data yang akan digunakan sebagai masukkan dari suatu sistem dan untuk memperoleh data yang berhubungan dengan perancangan sistem. Langkah-langkah yang dilakukan dalam perancangan sistem klinik ini adalah :

a. Analisis Kebutuhan Input

b. Analisis Kebutuhan Proses

c. Analisis Kebutuhan Ouput

d. Analisis Kebutuhan Perangkat Keras

Spesifikasi komponen perangkat keras yang digunakan untuk perancangan sistem ini sebagai berikut :

1. PC/Laptop dengan Prosesor Celeron.

2. RAM 2 GB 
3. Hardisk 40GB

4. Monitor

5. Mouse

6. Keyboard

\section{Diagram Konteks}

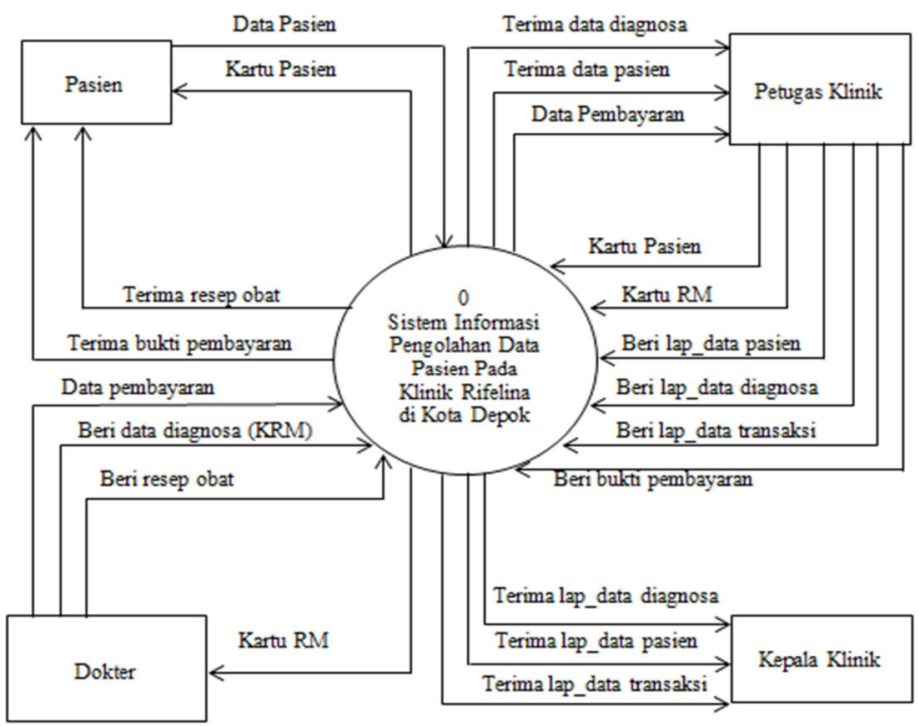

Gambar 1. Diagram Konteks Sistem Diusulkan

\section{Diagram Nol}

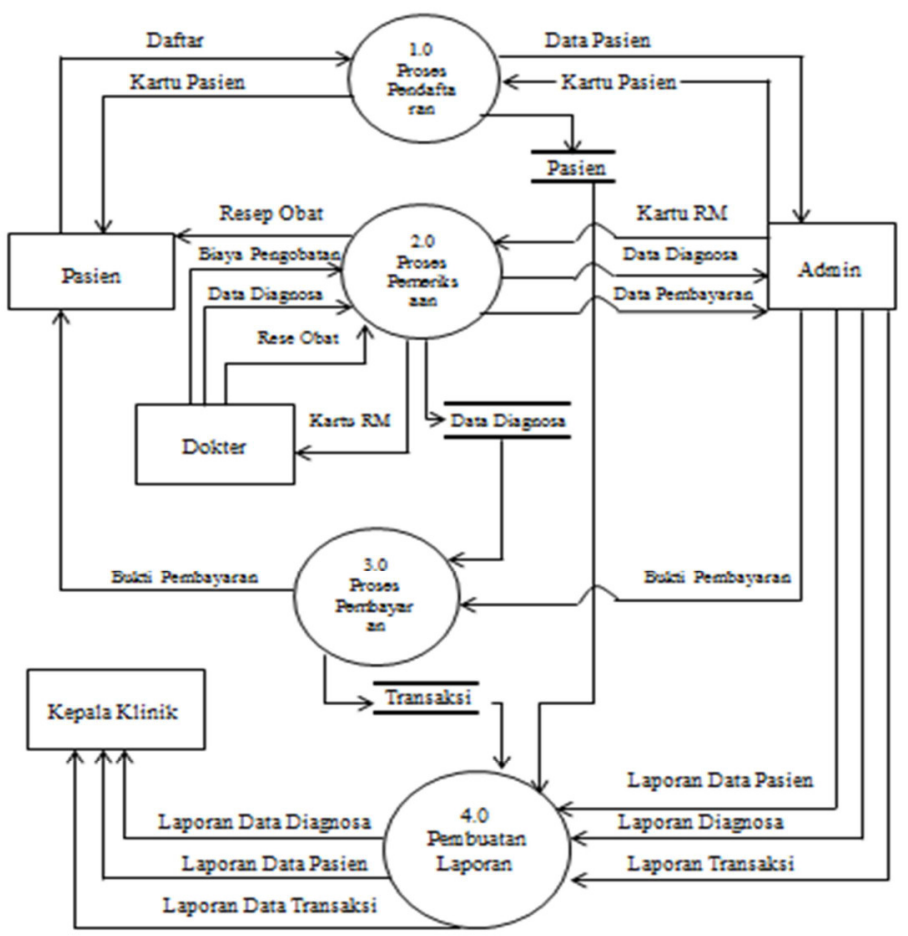

Gambar 2. Diagram Nol Sistem Diusulkan 


\section{ERD (Entity Relationship Diagram) Sistem Yang Diusulkan}

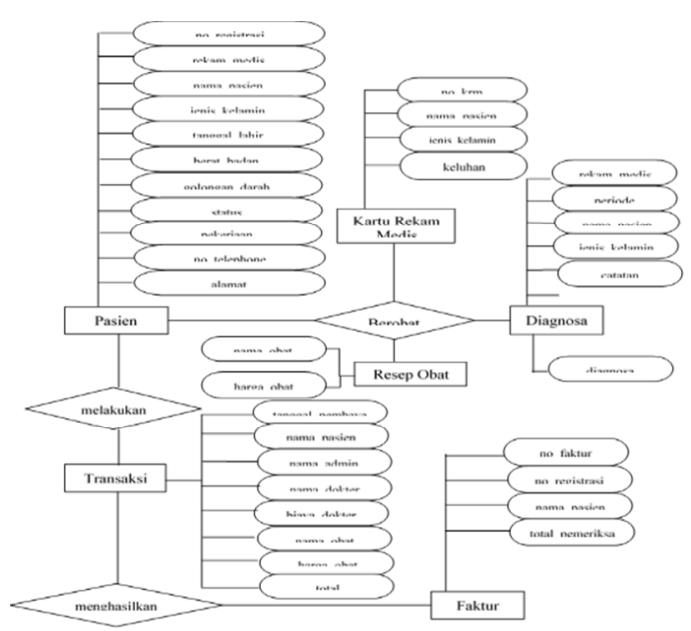

Gambar 7. ERD (Entity Relationship Diagram) Sistem Yang Diusulkan

\section{Perancangan Sistem}

Perancangan sistem bertujuan untuk merancang sistem yang akan dibuat agar dapat diimplementasikan dengan kebutuhan pengguna. Langkah-langkah yang dilakukan dalam perancangan sistem informasi klinik ini adalah :
a. Merancang database
b. Merancang antarmuka
c. Mengembangkan antarmuka
d. Validasi antarmuka

\section{Pengujian Program}

Pengujian software dilakukan untuk memastikan bahwa software yang dibuat telah sesuai dengan desainnya dan semua fungsi dapat dipergunakan dengan baik tanpa ada kesalahan. Sebelum sistem dapat digunakan, maka harus dilakukan pengujian terlebih dahulu. Dalam pengujian software ini peneliti menggunakan metode black box testing.

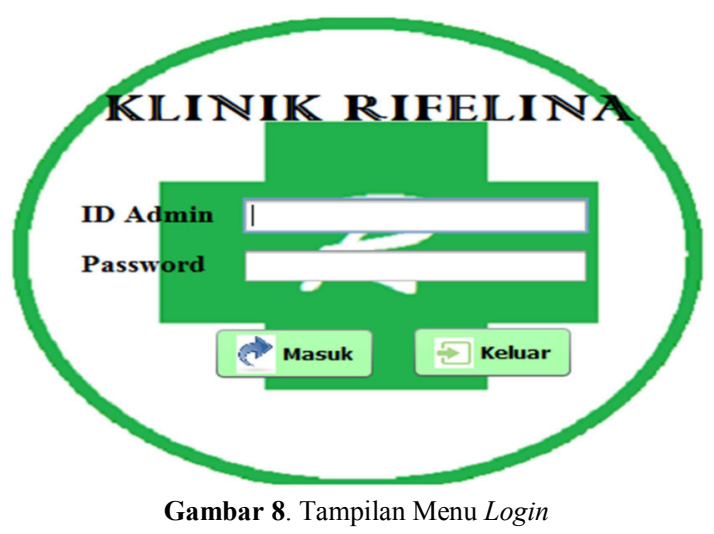

Pada gambar diatas terdapat menu login dimana menu login sebagai menu hak akses untuk user dapat mengakses aplikasi. 


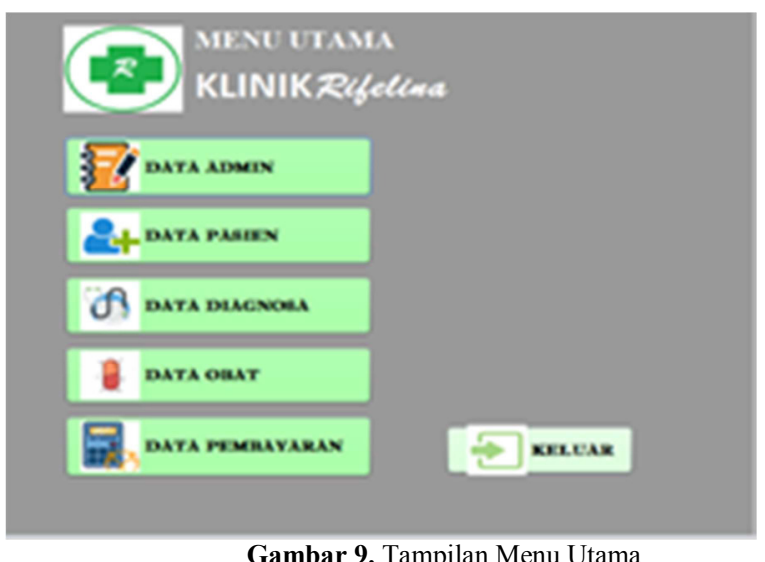

Setelah melakukan login, pada gambar diatas adalah menu halaman utama sebuah aplikasi.

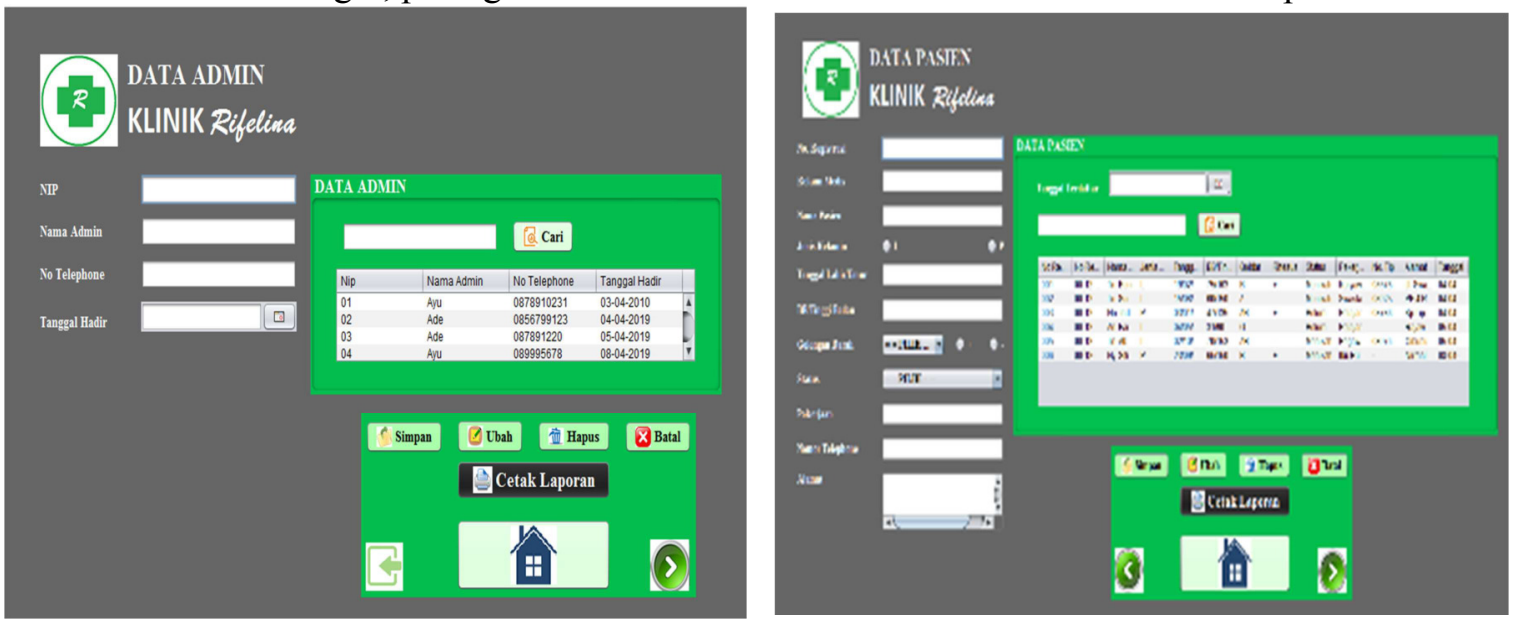

Gambar 10. Tampilan Data Admin dan Data Pasien

Pada gambar diatas merupakan menu tampilan data admin dan menu data pasien.
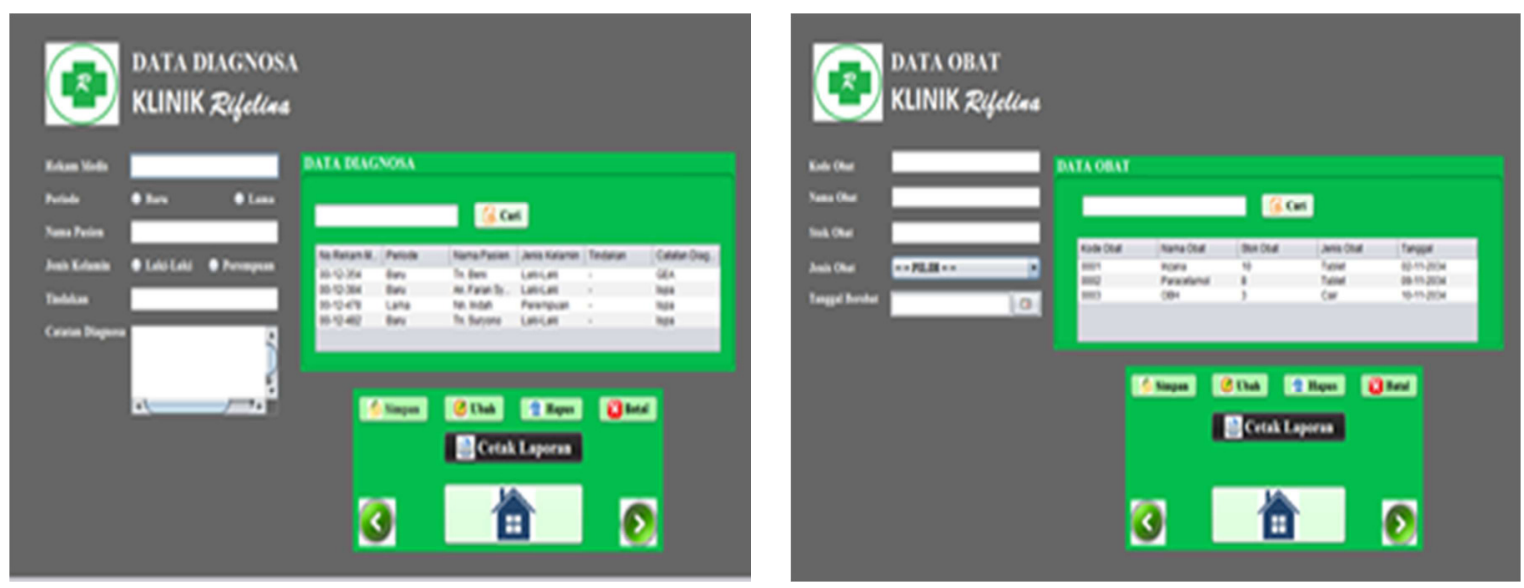

Gambar 11. Tampilan Data Diagnosa dan Data Obat

Pada gambar diatas merupakan tampilan menu data diagnose dan Petugas apoteker dapat memperbaharui Data Obat dengan mengakses form Data Obat. Pada form ini juga terdapat pengubahan dan penghapusan data obat yang ada. 


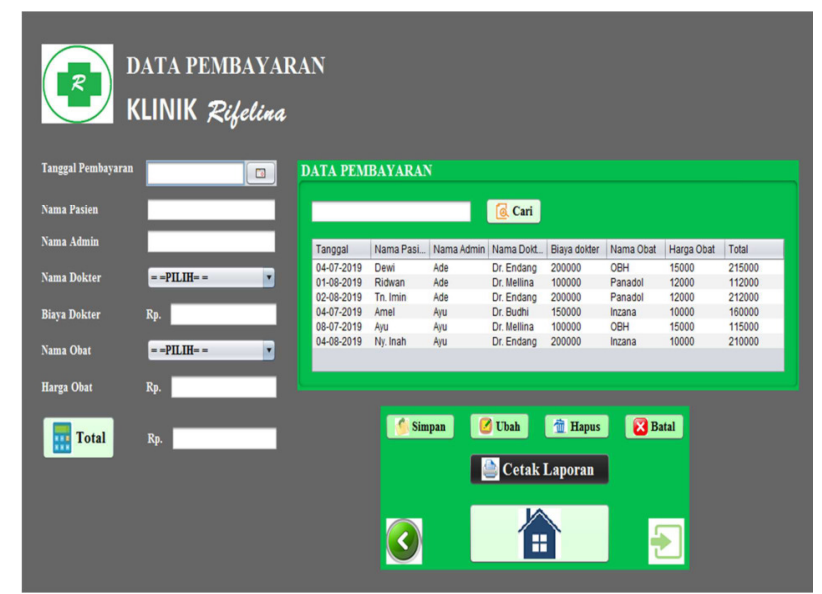

Gambar 12. Tampilan Data Pembayaran

Petugas loket pendaftaran mengisi Data Pembayaran
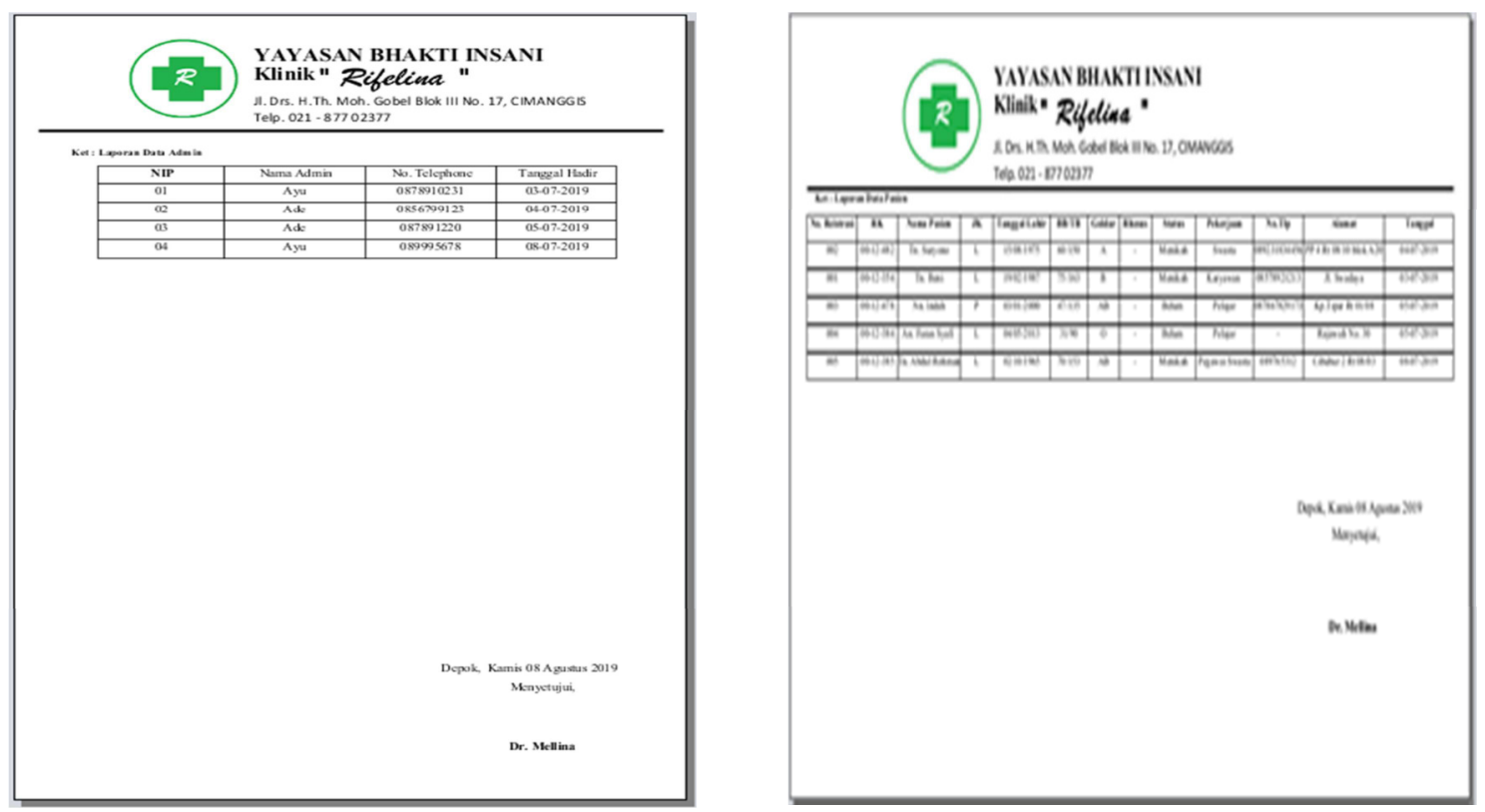

Gambar 13. Tampilan Laporan Data Admin dan Data Pasien

Laporan data admin berguna untuk mengetahui siapa saja yang hadir saat menjalankan tugas di klinik. Sedangkan laporan data pasien dapat di cetak melalui form data pasien. 

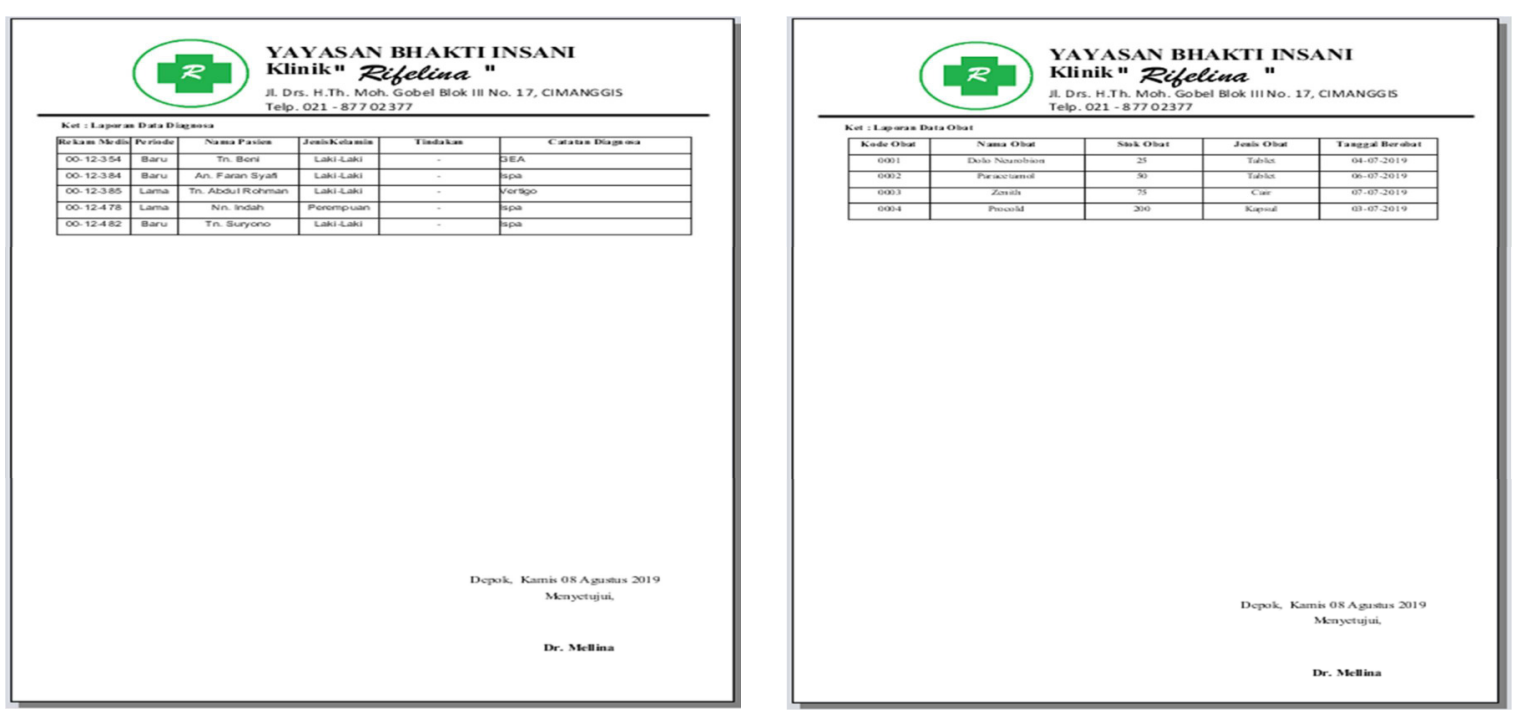

Gambar 14. Tampilan Laporan Data Diagnosa dan Data Obat

Laporan data diagnosa dapat di cetak melalui form data diagnose dan laporan di cetak setiap akhir bulan dan diserahkan ke pimpinan klinik.

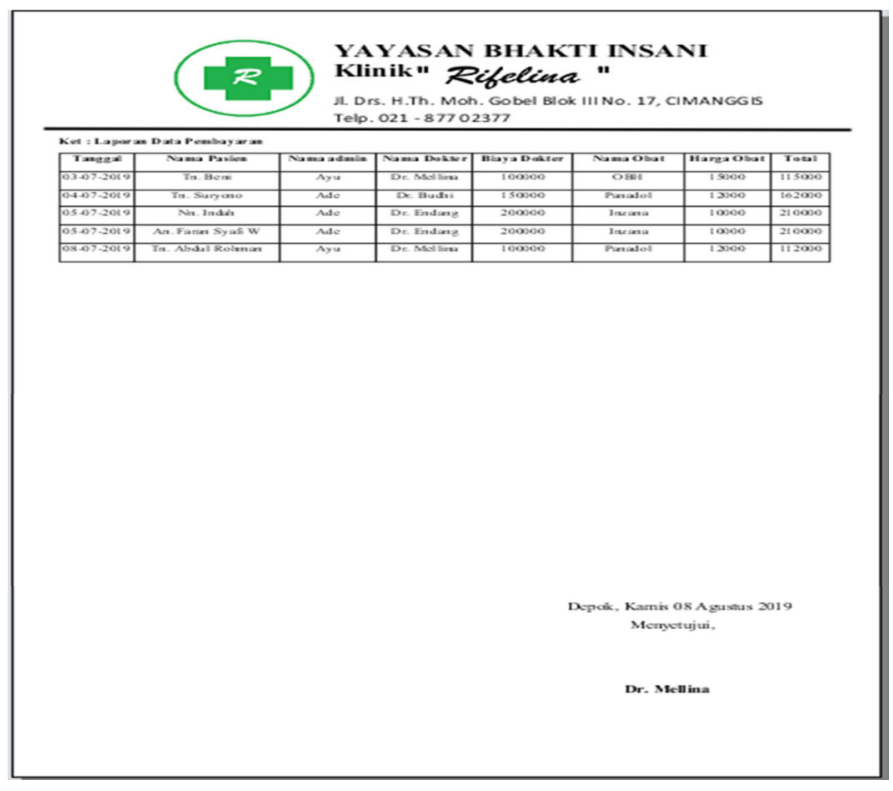

Gambar 15. Tampilan Laporan Data Pembayaran

Laporan di cetak setiap akhir bulan dan diserahkan ke pimpinan klinik.

\section{SIMPULAN}

Dengan adanya Rancangan Sistem Informasi Aplikasi Olah Data Pasien Pada Klinik Rifelina Kota Depok, semua kegiatan yang berhubungan dengan pengolahan data pasien berbasis Java NetBeans, agar dapat mempersingkat waktu pengolahan data transaksi klinik, sehingga pelayanan dapat dilakukan lebih mudah, cepat dan akurat sehingga pelayanan di klinik Rifelina Kota Depok lebih efektif dan efisien.

\section{DAFTAR PUSTAKA}

Irawan, D. (2017). Rancangan Sistem Layanan Informasi Pasien Quick Response Code Menggunakan Java Netbeans pada Klinik dr. Hasto Medika.

Jogiyanto. (2010). Analisa dan Desain Sistem Informasi. In Yogyakarta: Andi.

Nugroho, B. (2013). Dasar Pemrograman Web PHP - MySQL dengan Dreamweaver. Grava Media. 
Jurnal Riset dan Aplikasi Mahasiswa Informatika (JRAMI)

Vol 미 No Ul Tahun 2020

e-ISSN : $2715-8756$

Oktavia, D. A. (2017). Perancangan Sistem Informasi Pengolahan Data Pasien Klinik Dr. Delly Di Kabupaten Bogor Berbasis Java.

Rizky, S. (2011). Konsep Dasar Rekayasa Perangkat Lunak. In Konsep Dasar Rekayasa Perangkat Lunak.

Sukamto, Ariani, R., \& Shalahuddin, M. (2013). Modul Pembelajaran Rekayasa Perangkat Lunak (Terstruktur dan Berorientasi Objek).

Sutabri, T. (2012). Analisis Sistem Informasi. In Analisa Sistem Informasi. 